\title{
Ra mắt 8 nhóm nghiên cứu mạnh thuộc trường Đại học
}

Thu Cúc

16 May 2019

Báo Điện Tử Chính Phủ

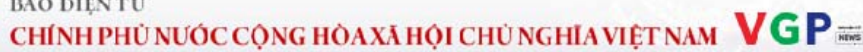

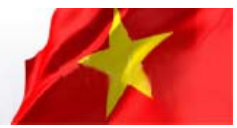

http://baodientu.chinhphu.vn/Khoa-hoc-Cong-nghe/Ra-mat-8-nhom-nghien-cuu-manh-thuoctruong-Dai-hoc/366038.vgp 


\title{
Ra mắt 8 nhóm nghiên cứu mạnh thuộc trường Đại học
}

\author{
$12: 22 \mathrm{CH}, 16 / 05 / 2019$
}

(Chinhphu.vn) - 8 nhóm nghiên cứu mạnh thuộc Trường Đại học Phenikaa tập hợp đội ngũ các nhà khoa học xuất sắc, hình thành những tập thể nghiên cứu mạnh có khả năng giải quyết các bài toán khoa học và công nghệ lớn, đi từ nghiên cứu cơ bản đến nghiên cứu phát triển và ứng dụng công nghệ.

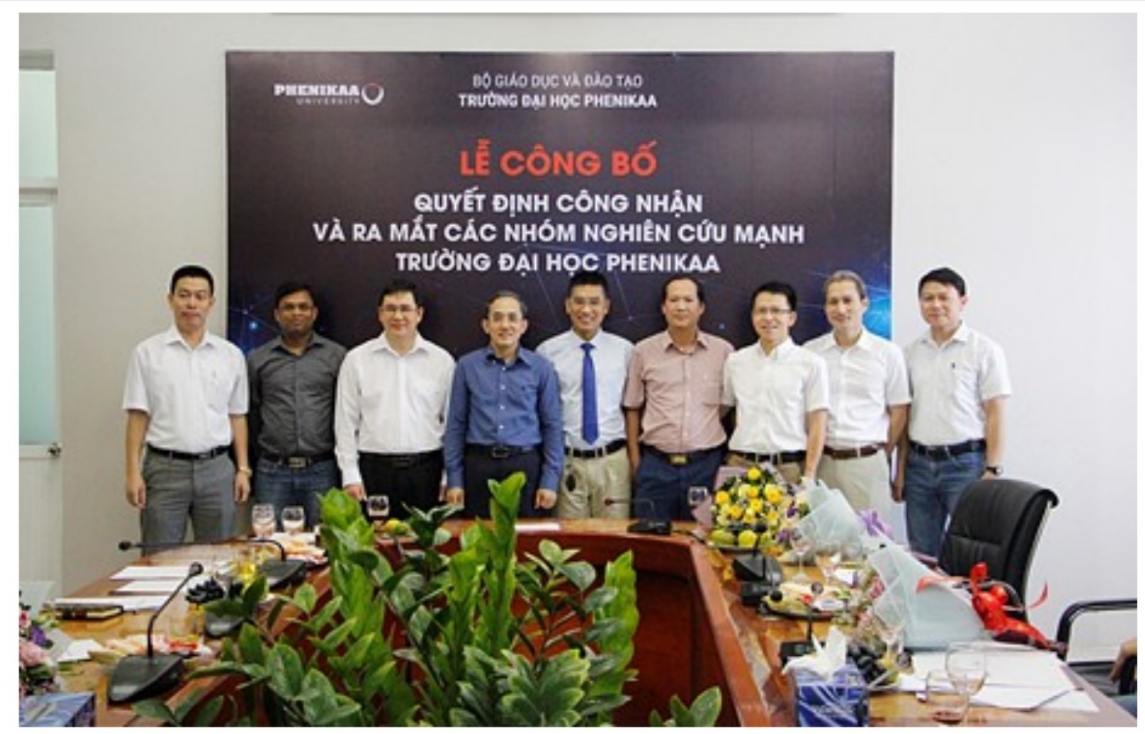

Trưởng các nhóm nghiên cứu mạnh là các nhà khoa học giàu kinh nghiệm và có nhiều công bố quốc tế. Ảnh: VGP

Hội đồng khoa học Trường Đại học Phenikaa vừa ra mắt 8 nhóm nghiên cứu mạnh nhằm tập hợp đội ngũ các nhà khoa học xuất sắc nghiên cứu các lĩnh vực: Vật liệu nano trong y sinh, môi trường và năng lượng; Hóa dược và Hoạt chất sinh học; Các hệ thống thông tin thông minh và Cảm biến nano; Quang tử và Quang điện tử; Vật lý năng lượng cao và Vũ trụ học và Phân tích dữ liệu lưới trong Khoa học xã hội.

8 trưởng nhóm nghiên cứu mạnh được lựa chọn đều là những nhà khoa học với nhiều công bố quốc tế và giàu kinh nghiệm dẫn dắt các nhóm nghiên cứu thành công, như GS.TS Phạm Thành Huy (Gương mặt Nhà khoa học trẻ tiêu biểu 1000 năm Thăng Long Hà Nội), GS.TS Nguyễn Văn Hiếu (Giải thưởng Tạ Quang Bửu, năm 2016), PGS.TS Phùng Văn Đồng (Giải thưởng Tạ Quang Bửu dành cho nhà khoa học trẻ, năm 2016), TS. Raja Das (JSPS Scholar - Nhật Bản, các năm 2018 và 2019). Các trưởng nhóm nghiên cứu mạnh được lựa chọn hiện đang là giảng viên cơ hữu và là các trưởng nhóm nghiên cứu tại trường.

Đặc biệt, các nhóm nghiên cứu mạnh được phân ra làm 2 loại hình: Nhóm nghiên cứu cơ bản và nhóm nghiên cứu ứng dụng.

Các tiêu chí đối với trưởng nhóm và các thành viên nghiên cứu chủ chốt thuộc mỗi loại hình cũng khác nhau. Kết quả nghiên cứu của các nhóm nghiên cứu mạnh cũng được yêu cầu cụ thể về số lượng và chất lượng công bố nhằm đảm bảo mục tiêu phát triển dài hạn và phát huy tối đa năng lực của các giảng viên, nhà khoa học trong trường. 
Nhóm nghiên cứu duy nhất trong lĩnh KHXH\&NV này do TS. Vương Quân Hoàng - Giám đốc Trung tâm nghiên cứu Khoa học xã hội liên ngành (ISR) của Trường làm trưởng nhóm. TS. Vương Quân Hoàng được xem là một trong những nhà khoa học hiếm hoi của Việt Nam có nhiều công bố quốc tế về lĩnh vực Khoa học xã hội.

Nhóm nghiên cứu ứng dụng đầu tiên tại Trường ĐH Phenikaa là nhóm nghiên cứu Quang điện tử và Quang tử của GS.TS. Phạm Thành Huy - người thường được giới khoa học nhắc tới nhiều trong việc xây dựng mô hình hợp tác nghiên cứu và chuyển giao công nghệ giữa trường đại học với doanh nghiệp.

Yêu cầu cụ thể đối với nhóm nghiên cứu mạnh trong lĩnh vực nghiên cứu cơ bản là mỗi năm phải công bố ít nhất 5 công trình khoa học là các bài báo trên các tạp chí hạng Q1 (theo tiêu chuẩn của SCImago Journal Rankings), hoặc 8 công trình khoa học trên các tạp chí quốc tế ISI/Scopus, trong đó có ít nhất 3 công trình hạng Q1. Mỗi công trình khoa học hạng Q1 có thể được thay thế bằng một sách chuyên khảo.

Đối với nhóm nghiên cứu mạnh trong lĩnh vực nghiên cứu ứng dụng, trong vòng 3 năm phải chuyển giao được ít nhất 1 quy trình công nghệ cho các doanh nghiệp (với tổng kinh phí chuyển giao công nghệ trên 500 triệu đồng), hoặc đăng ký thành công 2 sáng chế/giải pháp hữu ích trong nước hoặc quốc tế.

GS. Phạm Thành Huy, Hiệu trưởng Trường Đại học Phenikaa cho biết, với cả hai loại hình nhóm nghiên cứu đều yêu cầu các trưởng nhóm xây dựng kế hoạch phát triển dài hạn, trong đó khuyến khích các nhóm định hướng đến các sản phẩm cuối cùng bao gồm không chỉ các bài báo đăng trên tạp chí quốc tế, mà còn là các công nghệ mới, vật liệu mới, các linh kiện, hệ thống điều khiển, các máy móc, trang thiết bị đo đạc, sản xuất...

Theo GS. Phạm Thành Huy, với các nhóm nghiên cứu ứng dụng mạnh, yêu cầu thương mại hóa các kết quả hoặc đăng ký bản quyền sáng chế công nghệ là bắt buộc. Các hướng nghiên cứu ứng dụng có khả năng thương mại hóa sản phẩm cao sẽ được ưu tiên đầu tư và không giới hạn về kinh phí.

Mô hình chung của các nhóm nghiên cứu trên thế giới thường bao gồm trưởng nhóm là một giáo sư (nhà khoa học có uy tín), các phó giáo sư, nghiên cứu sau tiến sĩ (postdoc), nghiên cứu sinh, học viên cao học... Hoạt động của nhóm nghiên cứu cũng gắn với các định hướng nghiên cứu (cơ bản, ứng dụng) cụ thể, mang tính dài hạn và các đề tài, dự án nghiên cứu có mục tiêu, nội dung, kế hoạch triển khai và các sản phẩm khoa học, công nghệ và ứng dụng cụ thể.

Thu Cúc 